\title{
The price-to-book effect on the JSE: Valuation disparities and subsequent performance
}

\author{
S.G. du Toit and J.D. Krige* \\ Stellenbosch University, Private Bag X1, Matieland, 7602, South Africa \\ *To whom all correspondence should be addressed \\ jdkrige@sun.ac.za
}

\begin{abstract}
The purpose of this study was to determine whether the relative out- or underperformance of a value portfolio versus a growth portfolio can be anticipated in advance by comparing a valuation difference multiple with the subsequent fiveyear relative performance of the value and growth portfolios. The valuation difference multiple was calculated as the median price-to-book value $(\mathrm{P} / \mathrm{B})$ ratio of the growth portfolio divided by the median $\mathrm{P} / \mathrm{B}$ ratio of the value portfolio. Using monthly data for the period 1991 to 2011 , this study found that in most instances the higher the valuation difference multiple, the higher the outperformance of the value portfolio over the subsequent five-year period, as compared to the growth portfolio.
\end{abstract}

\section{Introduction}

During the past three decades many academic studies have found evidence supporting the premise that value investing outperforms growth investing over the longer term - both internationally (see for example Basu, 1983; Fama \& French, 1992; Lakonishok, Shleifer \& Vishny, 1994; Fama \& French, 1998) and in South Africa (see for example Fraser \& Page, 2000; Van Rensburg, 2001; Van Rensburg \& Robertson, 2003; Basciewitz \& Auret, 2009; Strugnell, Gilbert \& Kruger, 2011; Hoffman, 2012). However, value investing does not outperform growth investing on a consistent basis. As a result, a number of studies have been conducted in an attempt to identify variables that could possibly be indicative of a relative value or growth cycle in advance (see for example Mutooni \& Muller, 2007; Brandes Institute, 2009a; 2009b).

In their seminal article on style-based effects on the Johannesburg Stock Exchange (JSE) Muller and Ward (2013) included the performance of portfolios formed on the basis of their price-to-book ratios. They found that "On the basis of these observations we would conclude that low price-to-book ratios may at times have been advantageous, but, if they still exist, require timing skills" (Muller \& Ward, 2013:12). It is the purpose of this study to establish whether it is possible to improve these timing skills by identifying a relationship between characteristics inherent in a value investment style and subsequent stock market returns.

In this study all the stocks which are constituents of the FTSE/JSE All-Share Index were ranked according to their relative price-to-book value $(\mathrm{P} / \mathrm{B})$ ratios in order to create monthly value and growth portfolios for the period 1991 to 2011. The growth portfolios consisted of the highest $25 \%$ of $\mathrm{P} / \mathrm{B}$ ratio stocks, whilst the value portfolios consisted of the lowest $25 \%$ of $\mathrm{P} / \mathrm{B}$ ratio stocks. Stocks within the respective portfolios were equally weighted.

In order to determine whether a relationship existed between the $\mathrm{P} / \mathrm{B}$ ratio of the value portfolio and its subsequent relative performance, a valuation difference multiple was calculated on a monthly basis by dividing the median $\mathrm{P} / \mathrm{B}$ ratio of the growth portfolio by the median $\mathrm{P} / \mathrm{B}$ ratio of the value portfolio. This valuation difference multiple was compared with the subsequent annualized five-year excess return, where excess return was calculated as the difference between the annualized fiye-year returns of the value and growth portfolios. Once it had been determined whether a relationship existed between the valuation difference multiple and subsequent relative performance, it was necessary to establish how consistent this relationship was at various $\mathrm{P} / \mathrm{B}$ multiples. This was done by employing various statistical tests.

The remainder of this paper is organized as follows. Section 2 reviews the findings of similar international and South African studies. Section 3 discusses the data collection and methodology employed. Section 4 reports the results and Section 5 discusses some conclusions.

\section{Literature review}

Although many studies have shown that value stocks outperformed growth stocks in the long term, there have been certain sub-periods during which growth stocks outperformed value stocks. Christopherson and Williams (1997) showed that the equity market is better suited to a value style at times and at other times to a growth style. Therefore the risk for the value manager is in timing purchases to capitalize on an expected price appreciation, whereas the risk for the growth manager lies in the fact that the growth expected may not materialize. This was echoed 
by Bauman, Conover and Miller (1999). It is thus important to know which variables can be used for predicting the returns of a value strategy relative to a growth strategy. After Black and McMillan (2004) had constructed value and growth portfolios, certain market and macro-economic variables were observed in order to determine if they were related to either a growth or a value phenomenon. It was found by Black and McMillan (2004) that there is a nonlinear relationship between value and growth stocks on the one hand and certain market and macro-economic variables, such as industrial production, inflation rates as well as short and long term interest rates, on the other hand.

The most notable South African study investigating style timing strategies was conducted by Mutooni and Muller (2007). They developed an econometric model with three independent variables (viz: the 10 year versus the 5 year government bond yield spread, the gap between the ALSI earnings yield and the 10 year government bond yield and the index of coincident economic indicators) to predict style turning points. They showed that "timing the style spreads was a potentially more profitable strategy than buying and holding the index or (following a) simple (fixed) style strategy" (Mutooni \& Muller, 2007:23).

In 2009 the Brandes Institute published two articles on the relationship between the $\mathrm{P} / \mathrm{B}$ ratios of growth and value portfolios and subsequent five-year annualized excess returns of value versus growth portfolios (Brandes Institute, $2009 \mathrm{a} ; 2009 \mathrm{~b}$ ). The two articles were based on USA and non-USA developed markets respectively. It was found that historically a significant relationship existed between valuation disparities of value and growth stocks and their subsequent relative performance in both the USA and nonUSA developed markets.

To a large extent this study will be based on the novel approach followed by the Brandes Institute (2009a 2009b), applying the approach to South African data and extending the statistical analysis.

\section{Data and methodology}

\section{Data}

This study focused on the constituents of the All-Share Index on the grounds that these shares represented $99 \%$ of the market capitalization on the JSE, and are therefore of interest to institutional investors. Data was obtained from the JSE, McGregor BFA and 1-Net Bridge. The database was constructed in three broad steps.

Firstly, for the period 1991 to 1995 an All-Share Index was created, based on the new FTSE/JSE African Index Series construction methodology, in order to ensure that the same index construction methodology was used throughout the period of investigation. The JSE provided data on all the stocks that were listed on the JSE Main Board for the period 1991 through 1995; this included monthly prices and dividend yields. The number of ordinary shares outstanding at year end was extracted from the I-Net Bridge database. The ISE and I-Net Bridge data were combined in order to construct an All-Share Index for the period 1991 to 1995.

Secondly, for the period 1995 to 2002 the JSE provided back-tested All-Share data. This included a JSE back-test that backtracked market data to create an All-Share Index for the period 1995 to 2002 based on the new index calculation methodology. The back-test data served as the primary source of data for the period 1995 to 2002 . The JSE back-tested database included dividend yields for the period.

Finally, for the period 2002 through 2011 actual FTSE/JSE All-Share Index data was used. This data was supplied directly by the JSE and no alterations were necessary. It included price data, dividend yields and ordinary shares outstanding.

Apart from the above-mentioned data, book values of the constituents of the All-Share Index were primarily gathered from the BFA McGregor database. Standardized financial statement data, as provided by BFA McGregor, was used to extract relevant data.

\section{Methodology}

The methodology consisted of five broad steps. The first step was to create a database for all the constituents of the All-Share Index which included ordinary shares outstanding, book value per share, monthly prices and dividend yields.

Subsequently, P/B ratios of every stock included in the FTSE/JSE All-Share Index were calculated. The $\mathrm{P} / \mathrm{B}$ ratios were calculated every month by dividing the stock's month end price by its book value per share.

The second step in the research process was to rank the stocks according to their relative $\mathrm{P} / \mathrm{B}$ ratios. Subsequent to the ranking process, stocks were divided into four separate portfolios. The top $25 \%$ of $\mathrm{P} / \mathrm{B}$ ratio stocks formed the growth portfolio (quartile 1), while the bottom $25 \%$ of $\mathrm{P} / \mathrm{B}$ ratio stocks represented the value portfolio (quartile 4). Given the limited number of constituents of the All-Share Index, the top and bottom quartiles were used to form growth and value portfolios respectively. This differs from the Brandes Instutute (2009a) methodology, where the top and bottom deciles were used.

This step was repeated on a monthly basis during the research period. Due to the fact that subsequent five-year annualized performance was calculated, the last set of portfolios was constructed on 31 October 2006. The calculation of returns over five-year periods after portfolio formation is in line with the methodology employed by the Brandes Institute (2009a).

The third step in the research process was to calculate the subsequent five-year annualized return of each newly formed portfolio at month end. This was done by giving each stock in the respective portfolios equal weighting. 
Investment return was calculated on a monthly basis in the case of each portfolio. Each month the investment performance of each stock within its respective portfolio was calculated on the following basis:

$$
\text { Holding Period Return }{ }_{t}\left(\mathrm{HPR}_{\mathrm{t}}\right)=\frac{\mathrm{P}_{\mathrm{t}}-\mathrm{P}_{\mathrm{t}-1}+\mathrm{D}_{\mathrm{t}}}{\mathrm{P}_{\mathrm{t}-1}}
$$

where: $H \mathrm{PR}_{\mathrm{t}}=$ Total return in month $\mathrm{t}$;

$P_{t}=$ Price at the end of month $t$;

$\mathrm{P}_{\mathrm{t}-\mathrm{1}}=$ Price at the beginning of month $\mathrm{t}$;

$D_{t}=$ One-twelfth of the annual dividend yield at time t multiplied by $P_{t}$.

A buy-and-hold strategy was utilized. In instances where stocks had been delisted or were dropped from the FTSE/ISE All-Share Index, the proceeds were assumed to be invested equally in the remaining portfolio constituents as of the first day of the subsequent month. In order to compare returns with disparity in valuations, with the aim to identify a relationship, the five-year annualized excess return was calculated. Excess return was defined as the return of the value portfolio minus the return of the comparable growth portfolio. Sub-periods during which this value was positive were defined as value cycles, while a negative value was indicative of a growth cycle.

The fourth step in the research process was to calculate the following valuation difference multiple at each month end:

$$
\begin{aligned}
& \text { Valuation difference multiple } \mathrm{t}_{\mathrm{t}} \\
& =\frac{\text { Median } \frac{\mathrm{P}}{\mathrm{B}} \text { ratio of the growth (Q1)portfolio }_{\text {Median } \frac{\mathrm{P}}{\mathrm{B}} \text { ratio of the value (Q4)portfolio }}}{}
\end{aligned}
$$

Utilising the median growth $\mathrm{P} / \mathrm{B}$ ratio as the numerator and the median value $\mathrm{P} / \mathrm{B}$ ratio as the denominator, the multiple measures the relative disparity between the highest $\mathrm{P} / \mathrm{B}$ ratio stocks (growth) and the lowest $\mathrm{P} / \mathrm{B}$ ratio stocks (value) at a given point in time.

Step five in the research process was to compare the $\log$ of the valuation difference multiple with the corresponding five-year annualized excess return at each month end. This was done in order to determine whether a relationship existed between relative $\mathrm{P} / \mathrm{B}$ ratios and subsequent performance of value and growth stocks. The $\log$ of the valuation difference multiple was utilised, as the relationship between multiples and returns is not purely linear.

Subsequently the All-Cap sample was divided into LargeCap, Mid-Cap and Small-Cap segments using the FTSE/JSE classification to establish whether the possible relationship between the $\log$ of the valuation difference multiple and subsequent relative performance was consistent within each size segment. The same five steps were applied to these segments.

\section{Statistical tests}

A number of statistical tests were employed. The Augmented Dickey-Fuller test was utilised to test for the stationarity of the log of the valuation difference multiples and the excess return data series. It must be noted that the relatively short research horizon made testing for stationarity problematic since it is possible that stationarity may only be observed over longer periods of time. Bearing this limitation in mind the assumption of stationary data was validated by this test.

Data was further tested for the presence of serial correlation and heteroscedasticity. The Durbin-Watson test statistic was utilised to determine the presence of serial correlation. In the event of serially correlated error terms, autoregressive (AR) modelling techniques were employed to account for the presence of serial correlation. This was done by modelling appropriate AR models of the order one, AR(1), to the residuals. The Breusch-Pagan and Ljung-Box-Pierce tests (to the squared residuals) were conducted to detect the presence of heteroscedasticity. In the event of significant heteroscedasticity, autoregressive conditional heteroscedasticity (ARCH) and generalised autoregressive conditional heteroscedasticity (GARCH) models were employed to correct for heteroscedasticity in the residuals.

It was also thought necessary to test data for structural breaks. Initial structural breakpoints were identified through the Quants-Andrews unknown breakpoint test. Structural breakpoints as indicated by the Quants-Andrews test were confirmed with the Chow known breakpoint test. Periods after breakpoints were analysed to determine if identified trends remained present in the modern era.

Once these tests had been completed, relevant statistical values and linear regressions were used in order to determine whether a meaningful statistical relationship existed between the variables tested.

\section{Results}

\section{Performance based on the FTSE/JSE All-Share Index}

A significant positive relationship was found between the $\log$ of the valuation difference multiple and the subsequent five-year annualized excess return over the period 1991 to 2006 , with a t-statistic and p-value of 4,57 (critical value of $1,96)$ and 0,00 respectively. OLS estimates indicate that a one point increase in the valuation difference multiple was expected to be accompanied by an increase of $2,00 \%$ in the subsequent five-year annualized excess return. A DurbinWatson test statistic of 2,20 is sufficient to indicate uncorrelated residuals and thus proving that a meaningful statistical relationship exists.

Utilising the Quant-Andrews unknown breakpoint test and the Chow known breakpoint test, a structural breakpoint was identified in February 1996. It is likely that this structural 
breakpoint (and most of the other structural breakpoints discussed later in this study) is due to the significant restructuring of the JSE during 1994 and 1995. This included deregulation of the stock exchange, dismantling of exchange controls, the introduction of dual capacity trading and the alignment of tax laws with international trends (Mkhize \& Msweli-Mbanga, 2006). This resulted in a substantial increase in international funds flowing to South Africa and a subsequent higher correlation with international markets.

In order to establish the strength and consistency of the relationship during the period March 1996 to October 2006, a linear regression was conducted. The relationship between the five-year annualized excess return and the log of the valuation difference multiple is plotted in Figure 1.

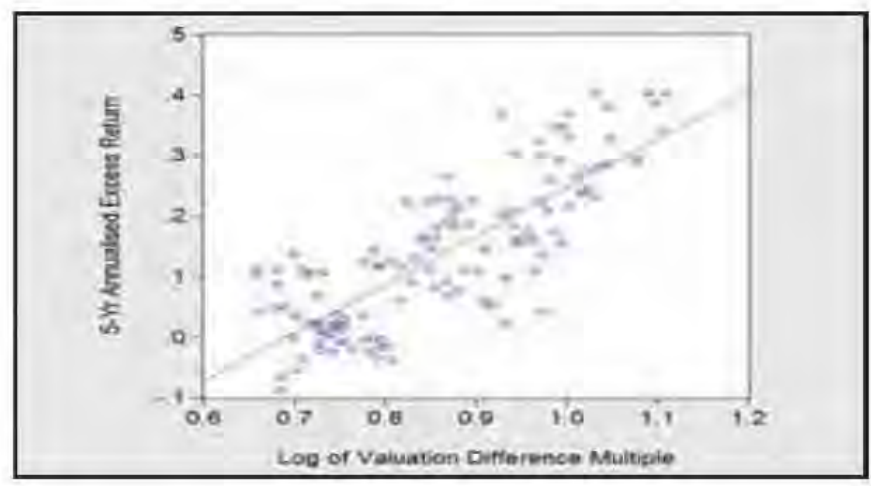

Figure 1: All-Cap linear regression line, Mar96 - Oct06

The upward sloping trend line in Figure 1 indicates a strong positive relationship between the five-year annualized excess return and the $\log$ of the valuation difference multiple. Special mention should be made of the high positive correlation coefficient of 0,80 between the variables.

A linear regression estimation utilising Ordinary Least Squares (OLS) was subsequently done, with the five-year annualized excess return representing the dependent variable (Y) and the $\log$ of the valuation difference multiple representing the independent variable $(X)$.
Table 1: All-Cap OLS estimation ontput, Mar96 - Oct06

\begin{tabular}{|c|c|c|c|c|}
\hline \multicolumn{5}{|c|}{$\square$ Equation: EQ02 Worlefile: ALSI96-06:Untitied } \\
\hline \multicolumn{5}{|c|}{$\begin{array}{l}\text { Dependent Variable: Y } \\
\text { Method: Least Squares } \\
\text { Date: 02/21/12 Time: } 15: 12 \\
\text { Sample (adjusted): } 1996 \mathrm{M04} \text { 2006M10 } \\
\text { Included observations: } 127 \text { after adjustments } \\
\text { Convergence achieved after } 7 \text { iterations }\end{array}$} \\
\hline & Coefficient & Sta. Error & $\mathrm{t}$-Statistic & Prob. \\
\hline $\begin{array}{c}c \\
x \\
A R(1)\end{array}$ & $\begin{array}{r}-0.133637 \\
0.277506 \\
0.972005\end{array}$ & $\begin{array}{l}0.097526 \\
0.054203 \\
0.024459\end{array}$ & $\begin{array}{r}-1.370272 \\
5.119789 \\
39.74036\end{array}$ & $\begin{array}{l}0.1731 \\
0.0000 \\
0.0000\end{array}$ \\
\hline $\begin{array}{l}\text { R-squared } \\
\text { Adjusted R-squared } \\
\text { S.E of regression } \\
\text { Sum squared resid } \\
\text { Log likelihood } \\
\text { F-statistic } \\
\text { Prob(F-statistic) }\end{array}$ & $\begin{array}{l}0.954278 \\
0.953541 \\
0.026219 \\
0.085243 \\
283.7539 \\
1294.023 \\
0.000000\end{array}$ & $\begin{array}{l}\text { Mean depen } \\
\text { S.D depend } \\
\text { Akaike info c } \\
\text { Schwarz crits } \\
\text { Hannann-Qui } \\
\text { Durbin-Wats }\end{array}$ & $\begin{array}{l}\text { ent var } \\
\text { nt var } \\
\text { terion } \\
\text { ion } \\
\text { n criter } \\
\text { a stat }\end{array}$ & $\begin{array}{r}0.136089 \\
0.121641 \\
-4.421321 \\
-4.354136 \\
-4.394024 \\
2.078833\end{array}$ \\
\hline Inverted AR Roots & 97 & & & \\
\hline
\end{tabular}

Table 1 represents the regression output after autoregressive modelling techniques had been utilised to account for the presence of serial correlation. A Durbin-Watson test statistic of 2,08 is sufficient to indicate uncorrelated residuals and thus that a valid significant relationship has been found. Further evidence of the strong relationship is the high tstatistic of 5,12 (critical value of 1,96 ) and $p$-value of 0,00 . Both the $R^{2}$ and adjusted $R^{2}$ indicate that roughly $95 \%$ of the variance in excess return is explained by the valuation difference multiple. OLS estimates indicate that a one point increase in the valuation difference multiple was expected to be accompanied by an increase of $2,78 \%$ in the subsequent five-year annualized excess return.

Performance based on constituent indices of the FTSE/JSE All-Share Index

\section{FTSEIJSE TOp-40 index}

A significant positive relationship was found between the log of the valuation difference multiple and the subsequent five-year annualized excess return over the period 1991 to 2006 , with a t-statistic and $p$-value of 5,57 (critical value of 1,96 ) and 0,00 respectively. OLS estimates indicated that a one point increase in the valuation difference multiple was expected to be accompanied by an approximate increase of $1,51 \%$ in the subsequent five-year annualized excess return. Autoregressive estimation techniques and GARCH models were applied to account for serial correlation and conditional heteroscedasticity. A Durbin-Watson test statistic of 2,29 is believed to be indicative of uncorrelated residuals, thus it was concluded that a valid statistical relationship existed.

The process of testing for structural breakpoints within the FTSE/JSE Top-40 Index data identified two independent breakpoints. The first breakpoint was identified in December 1996 and the second in February 2002. 


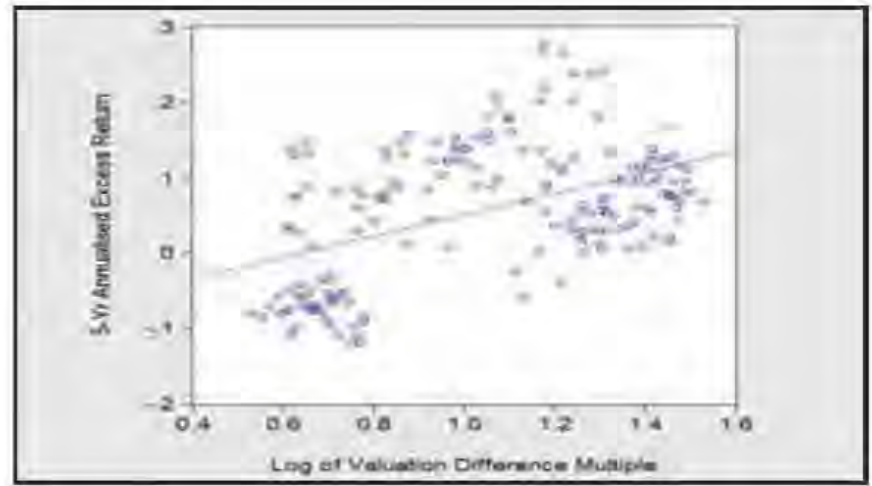

Figure 2: Large-Cap linear regression line, Jan91 Oct06

Figure 2 clearly indicates three separate clusters on the scatter plot of the five-year annualized excess returns and the valuation difference multiples. The upward sloping regression line indicates a positive relationship over the entire research period, but upon further investigation it became clear that significant structural changes occurred. The bottom right hand cluster contains almost all of the data points prior to December 1996, with the bottom left hand cluster containing data points post the February 2002 breakpoint. The top left hand cluster contains the majority of the data points between the two breakpoints. The bottom right hand and top left hand clusters showed a positive significant relationship between the five-year annualized excess returns and the valuation difference multiples. However, this could not be confirmed for the bottom left hand cluster. It is possible that this result is due to the small size of the sample, and the fact that the correlation between large cap value and growth stocks increased significantly in the period after the February 2002 structural breakpoint.

\section{FTSE/JSE Mid-Cap index}

A significant positive relationship was found between the $\log$ of the valuation difference multiple and the subsequent five-year annualized excess return over the period 1991 to 2006 , with a t-statistic and p-value of 3,58 (critical value of $1,96)$ and 0,00 respectively. The OLS estimates indicated that a one point increase in the valuation difference multiple was expected to be accompanied by an increase of $1,81 \%$ in the subsequent five-year annualized excess return. Autoregressive modelling techniques were utilised to account for the presence of serial correlation in the error terms.

Subsequent to confirming the positive relationship between the five-year annualized excess return and the valuation difference multiple, data was tested for the presence of structural breakpoints. A breakpoint was identified in July 1997.

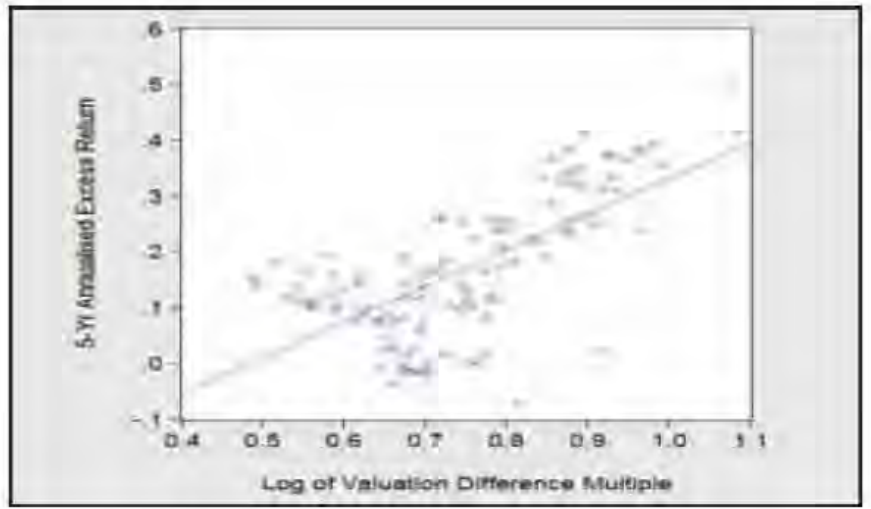

Figure 3: Mid-Cap linear regression line, Aug97 - Oct06

Figure 3 indicates a robust positive relationship between the five-year annualized excess return and the $\log$ of the valuation difference multiple, which is confirmed by a correlation coefficient of 0,68 .

Table 2: Mid-Cap OLS estimation ontpnt, Aug97 Oct06

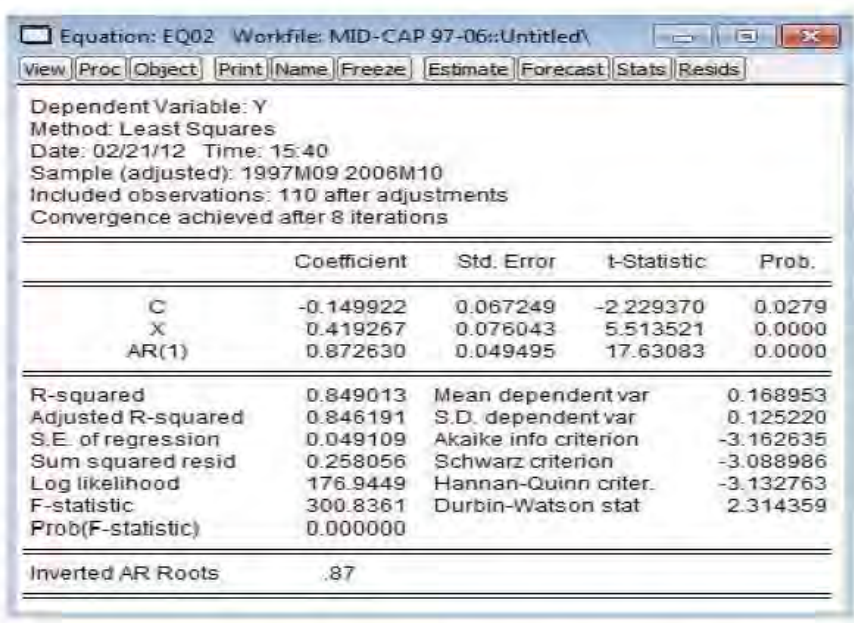

The linear regression results in Table 2 confirm a strong relationship between the five-year annualized excess return and the valuation difference multiple over the period August 1997 to October 2006. Evidence of the significant relationship is given by the t-statistic of 5,51 (critical value of 1,96 ) and $p$-value of 0,00 . Both the $R^{2}$ and adjusted $R^{2}$ indicate that roughly $85 \%$ of the variance in excess return is explained by the valuation difference multiple. Autoregressive modelling techniques were utilized to account for the presence of serial correlation, resulting in a Durbin-Watson test statistic of 2,31 , which supports the validity of the findings as it can be concluded that residuals are uncorrelated. The model predicted that a one point increase in the valuation difference multiple should lead to an approximate increase of $4,19 \%$ in the subsequent fiveyear annualized excess return. 


\section{FTSE/JSE SMall-Cap index}

A significant positive relationship was found between the $\log$ of the valuation difference multiple and subsequent fiveyear annualized excess return over the period 1991 to 2006. Applying autoregressive modelling techniques to account for serial correlation and heteroscedasticity, a significant $t$ statistic and $p$-value of 3,20 (critical value of 1,96 ) and 0,00 respectively were obtained. A Durbin-Watson test statistic of 2,00 supported the validity of the findings, indicating that the residuals were indeed uncorrelated. The OLS estimates indicated that a one point increase in the valuation difference multiple was expected to be accompanied by an increase of $1,83 \%$ in the subsequent five-year annualized excess return.

A structural breakpoint was identified in May 1997 within the FTSE/JSE Small-Cap Index data.

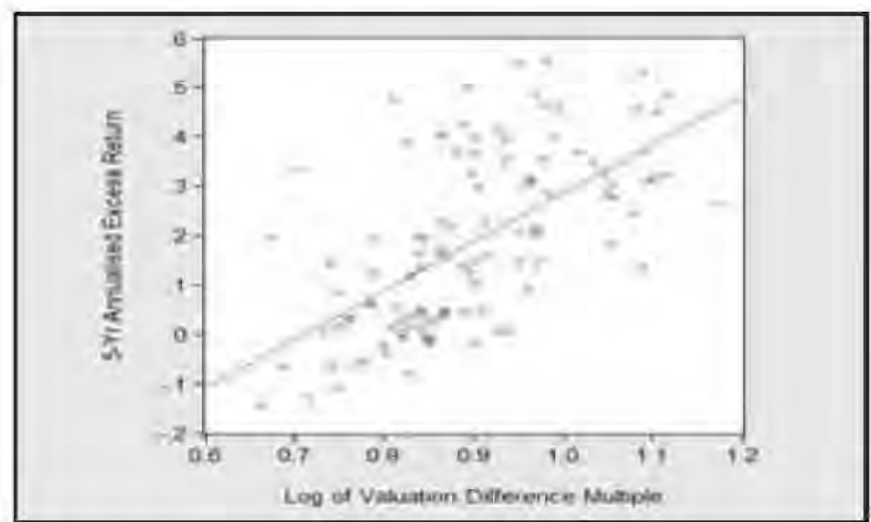

Figure 4: Small-Cap linear regression line, Jun97 Oct06

In Figure 4 the relationship between the five-year annualized excess return and the valuation difference multiple is plotted. The upward sloping regression line indicates a strong positive relationship between the variables, which is confirmed by a correlation coefficient of 0,62 .

Table 3: Small-Cap OLS estimation ontput, Jun97 Oct06

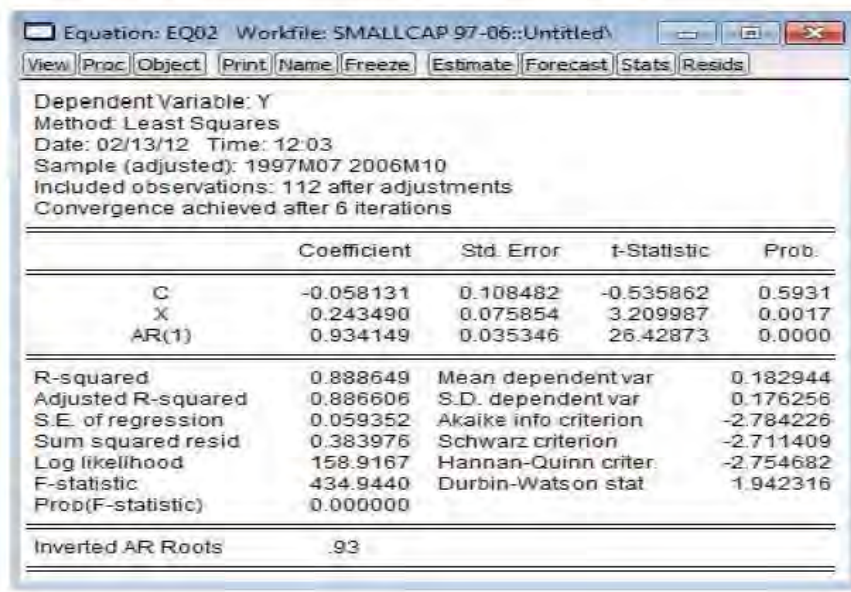

The linear regression results in Table 3 indicate a strong positive relationship between the five-year annualized excess return and the valuation difference multiple over the period July 1997 to October 2006. The significance of the relationship is confirmed by a t-statistic of 3,21 (critical value of 1,96 ) and a p-value of 0,00 . Autoregressive modelling techniques were utilized to account for serial correlation, resulting in a Durbin-Watson test statistic of 1,94 , which supported the validity of the findings, as it can be concluded that the residuals are uncorrelated. Both the $\mathrm{R}^{2}$ and the adjusted $\mathrm{R}^{2}$ indicate that roughly $89 \%$ of the variance in excess return is explained by the valuation difference multiple. According to the OLS estimates provided in Table 3 , a one point increase in the valuation difference multiple was expected to be accompanied by an increase of approximately $2,43 \%$ in the subsequent five-year annualized excess return.

\section{Conclusions}

The purpose of this study was to determine whether the relative out- or underperformance of a value portfolio versus a growth portfolio can be anticipated in advance by comparing a valuation difference multiple with the subsequent five-year relative performance of the value and growth portfolios. The valuation difference multiple was calculated as the median $\mathrm{P} / \mathrm{B}$ ratio of the growth portfolio divided by the median $\mathrm{P} / \mathrm{B}$ ratio of the value portfolio.

Using monthly data for the period 1991 to 2011 , this study found that the higher the valuation difference multiple, the higher the outperformance of the value portfolio over the subsequent five-year period, as compared to the growth portfolio.

This study also found that this statistically significant positive relationship existed in both the All-Cap sample as well as the Large-Cap, Mid-Cap and Small-Cap segments over the full period of the investigation.

Utilising the Quant-Andrews unknown breakpoint test and the Chow known breakpoint test, structural breakpoints were identified for each of the four segments. It was found that a statistically significant positive relationship existed for the periods after the structural breakpoints in the case of the All-Cap sample as well as the Mid-Cap and Small-Cap segments, which confirmed that the identified trends remained present in the modern era. However, although this positive relationship existed in the case of the Large-Cap segment between the structural breakpoints in December 1996 and February 2002, it could not be confirmed for the period after the structural breakpoint in February 2002.

\section{References}

Basiewicz, C. \& Auret, C. 2009. 'Feasibility of the Fama and French three factor model in explaining returns on the JSE', Investment Analysts Journat, 74: 29-37. 
Basu, S. 1983. 'The relationship between earnings yield, market value and return for NYSE common stocks', Joumal of Financial Economics, 12; 129-156.

Bauman, W.S., Conover, C.M. \& Miller, R.E. 1999. "Growth versus value and large-cap versus small-cap stocks in international markets', Financial Analysts Joumal, 54(2): $75-89$.

Black, A.J, \& McMillan, D.G. 2004. Non-linear predictability of value and growth stocks and economic activity, Journal of Business Finance and Accounting, 31: 439-474.

Brandes Institute. 2009a. Value vs. glamour revisited: Historical $P / B$ ratio disparities and subsequent value stock outperformance. [online] URL: http://www.brandes.com/ Institute/Documents/Value $\% 20 \mathrm{vs} \% 20$ Glamour $\% 20$ Revisite d.pdf.

Brandes Institute. 2009 b. Value vs. glamour revisited: Historical $P / B$ ratio disparities and subsequent value stock outperformance in non-U.S. markets. [online] URL:

http://www.brandes.com/Institute/Documents/Value $\% 20 \mathrm{vs}$ $\%$ 20Glamour $\% 20$ Revisited-PB $\% 20$ Rations $\% 20$ NonUS\%20112009.pdf

Christopherson, J.A. \& Williams, C.N. 1997. Equity style: What is it and why it matters. In Fabozzi. F.J. (Ed.). The Handbook of Equity Style Management. New Hope, PA.

Fama, E.F. \& French, K.R. 1992. 'The cross-section of expected stock returns', The Journal of Finance, 47(2): 427465.

Fama, E.F. \& French, K.R. 1998. 'Value versus growth: The international evidence', The Journal of Finance, 53(6): 1975-1999.

Fraser, E. \& Page, M. 2000. "Value and momentum strategies: Evidence from the Johannesburg Stock Exchange', Investment Analysts Journal, 51: 15-30.

Hoffman, A. 2012. 'Stock return anomalies: Evidence from the Johannesburg stock exchange', Investment Analysts Journal, 75: 21-41.

Lakonishok, I., Shleifer, A. \& Vishny, R.W. 1994. 'Contrarian investment, extrapolation, and risk', The Journal of Finance, 49(5): 1541-1578.

Mkhize, H. \& Msweli-Mbanga, P. 2006. 'A critical review of the restructuring of the South African capital market', International Review of Business Research Report, 2(2): 8091.

Mutooni, R. \& Muller, C. 2007. 'Equity style timing', Investment Analysts Journal. 49: 5-17.
Muller, C. \& Ward, M. 2013. ' Style-based effects on the Johannesburg stock exchange; A graphical time-series approach', Investment Analysts Journal, 77: 1-16.

Strugnel1, D., Gilbert, E. \& Kruger, R. 2011. 'Beta, size and value effects on the JSE, 1994-2007, Investment Analysts Journal, 74: 1-17.

Van Rensburg, P. 2001. 'A decomposition of style-based risk on the JSE', Investment Analysts Journal, 54: 45-60.

Van Rensburg, P. \& Robertson, M. 2003. 'Size, price-toearnings and beta on the JSE Securities Exchange', Investment Analysts Journal, 58: 7-16. 